\title{
Immunohistological study of human lungs by immunoperoxidase technique
}

\author{
BERNARD FOX, SAMI SHOUSHA, KEITH R JAMES, GILLIAN C MILLER \\ From the Department of Histopathology, Charing Cross Hospital Medical School, London W6 8RF
}

SUMMARY An unlabelled antibody peroxidase-antiperoxidase method for the detection of IgG, IgM, complement (C3 and $\mathrm{Clq}$ ), fibrinogen and albumin was applied to routinely processed paraffin sections of lung from 27 cases. The results in 11 cases were compared with those obtained by immunofluorescence using frozen sections. Tissue was obtained from surgical specimens of cases with interstitial pneumonia comprising 10 of the usual type (UIP) and three of the desquamative type (DIP). Tissue was also obtained from the specimens of cases with sarcoidosis (two cases) and granulomatous inflammation of unknown cause (one case).

There were 11 control cases, nine with primary carcinoma of the lung and two with metastatic tumours of the lung.

Immunoglobulins of various types and complement were seen in diseased lung tissue. Although most of these deposits were probably due to a non-immunological mechanism there was evidence of the possible implication of immune complexes in three cases of UIP and in the interstitial pneumonia present in the two cases of sarcoidosis.

The immunoperoxidase technique is a more sensitive method than immunofluorescence and has the additional advantage of the easy identification of the precise sites of the various deposits.

Immunological mechanisms are known to be associated with various lung diseases. ${ }^{1}$ In some of these, immune deposits have been demonstrated by immunofluorescence in tissue sections and this is thought to be useful in diagnosing and explaining the pathogenesis of such diseases. Examples include Goodpasture's syndrome, ${ }^{2-10}$ hypersensitivity pneumonitis, ${ }^{811-13}$ idiopathic interstitial pneumonia, ${ }^{814-16}$ fulminating interstitial pneumonia, ${ }^{17}$ and lung diseases associated with rheumatoid arthritis, ${ }^{18}$ systemic lupus erythematosus, ${ }^{19-26}$ angioimmunoblastic lymphadenopathy, ${ }^{27}$ chronic active hepatitis $^{28}$ and idiopathic thrombocytopenic purpura. ${ }^{29}$

Immunofluorescence entails the use of frozen sections and specially equipped microscopes. The fluorescence may fade; it is sometimes difficult to identify the exact site of the deposit, and the size of each block of tissue that can easily be examined is relatively small. Immunoperoxidase techniques are supposed to be devoid of all these drawbacks and are now widely used for the detection of various antigens in different tissues. ${ }^{30-31}$ Recently, Inoue et $a l^{26}$ have successfully used an immunoperoxidase method for the detection of immunoglobulins, complement and DNA in frozen sections of lung tissue from two patients with systemic lupus erythematosus. We report the results of an investigation into the feasibility of using an immunoperoxidase technique for the detection of immunoglobulins, complement and fibrinogen in fixed, routinely processed paraffin sections of lung. The results obtained by the immunoperoxidase technique were compared with those obtained by immunofluorescence.

\section{Material and methods}

Details of the patients from whom the specimens were obtained are given in the Table. The tissues examined were all obtained at thoracotomy; either biopsy, lobectomy or pneumonectomy specimens (Table). The classification of interstitial pneumonia follows that described by Liebow and Carrington; ${ }^{32}$ the desquamative type (DIP) and the usual type (UIP) which corresponds to the mural type as described by Scadding and Hinson. ${ }^{33}$ Cases 17-27 acted as controls. The tissue examined from 
cases 21-27 was taken from normal parts of the lung some distance away from the carcinoma or metastatic deposits. The histological diagnosis (Table) was made on haematoxylin and eosin stained sections taken from the same blocks as that used for the immunoperoxidase tests.

The activity of interstitial pneumonia present was graded according to the intensity of the inflammatory reaction (macrophages, plasma cells, lymphocytes, neutrophils and eosinophils) in the interstitial tissue. This was done by two observers without knowledge of the immunological results. Grade + indicated the presence of many inflammatory cells, \pm moderate numbers and - none, or only an occasional cell (Table).

IMMUNOPEROXIDASE TECHNIQUE (IP)

The tissues were fixed in $10 \%$ formalin for at least $24 \mathrm{~h}$. Routine paraffin embedding was carried out and $5 \mu \mathrm{m}$ sections cut and kept at $37^{\circ} \mathrm{C}$ in an incubator for a minimum of $24 \mathrm{~h}$. Sections were then dewaxed and hydrated to Tris-buffered saline pH 7.6 (TBS). An unlabelled antibody (peroxidaseantiperoxidase) technique after trypsinisation was then carried out.

The sections were incubated at $37^{\circ} \mathrm{C}$ for $30 \mathrm{~min}$ in $0.1 \%$ solution of trypsin in $0.1 \%$ calcium chloride in TBS freshly prepared and preheated to $37^{\circ} \mathrm{C}$ just before use, and then washed with gentle agitation in TBS for $5 \mathrm{~min}$. The endogenous peroxidase was blocked by applying freshly prepared $0.5 \%$ hydrogen peroxide in methanol for $30 \mathrm{~min}$ at room temperature, followed by washing with agitation in three ten minute changes of TBS. Non-immune normal swine serum, diluted 1/10 TBS, was applied for 10 min and then drained. Specific rabbit antihuman serum was applied for $30 \mathrm{~min}$ in a moist chamber at room temperature.

In the first five cases, various concentrations of antisera were tried and the highest concentration that gave a positive result without background staining was subsequently used. These were $1 / 1000$ for anti-IgG, IgA and $\operatorname{IgM}, 1 / 500$ for $\mathrm{C} 3$ and fibrinogen, $1 / 100$ for $\mathrm{Clq}$ and $1 / 8000$ for albumin. The sections were then washed in TBS for $10 \mathrm{~min}$ with agitation and this was repeated three times. Swine antirabbit immunoglobulin, diluted $1 / 100$ with TBS, was applied for $\mathbf{3 0} \mathrm{min}$ in a moist chamber at room temperature. This was followed by three washes of $10 \mathrm{~min}$ each with TBS and then peroxidaseantiperoxidase complex (PAP) diluted 1/100 with TBS was applied for 30 min in a moist chamber at room temperature. After three ten minute washes with TBS, DAB reagent (see below) was applied for $10 \mathrm{~min}$.

Sections were then washed in running tap water for $3 \mathrm{~min}$. The sections were counterstained with haematoxylin for $2 \mathrm{~min}$, washed in tap water for one minute, differentiated in $1 \%$ acid alcohol, 2-3 dips, and "blued" in running tap water for $10 \mathrm{~min}$. After dehydration, the sections were cleared and mounted in a synthetic resin. The peroxidase reaction site was dark brown and nuclei blue. Positive and negative controls were included with each tested set of slides. Positive controls were sections of tonsillar tissue known to be positive for all classes of immunoglobulins being used. Negative controls were sections of test lung tissue in which the step using specific antihuman antiserum was omitted.

REAGENTS

(a) DAB: $50 \mathrm{mg} 3,4,3^{\prime}, 4^{\prime}$ tetra-aminobiphenylhydrochloride dissolved in $100 \mathrm{ml}$ TBS, then filtered; $0 \cdot 1 \mathrm{ml} \mathrm{30 \%}$ (100 vols) hydrogen peroxide was added just before use.

(b) Trypsin 1/250 obtained from Difco Laboratories, Surrey, England.

(c) All specific sera and antisera used were Dako products obtained from Mercia Brocades Ltd, Surrey, England.

IMMUNOFLUORESCENT TECHNIQUE (IF)

A piece of unfixed lung tissue approximately $1.0 \times$ $0.5 \times 0.5 \mathrm{~cm}$ taken immediately after surgical removal was mounted with Tissue-Tek 11 OCT compound (Miles Laboratories Incorporated, USA) on to cork mats and snap-frozen with $\mathrm{CO}_{2}$ gas. Serial sections of the frozen tissue block were cut on a cryostat at a thickness of about $6 \mu \mathrm{m}$. Two serial sections were mounted on each of 10 clean slides and allowed to dry at room temperature for $30 \mathrm{~min}$ and then fixed in acetone for $15 \mathrm{~min}$ and dried in air. The sections were washed thoroughly in phosphatebuffered saline $\mathrm{pH} 7 \cdot 6$ (PBS) for $10 \mathrm{~min}$ and specific rabbit antihuman sera conjugated with fluorescein isothiocyanate (FITC) diluted $1 / 10$ with PBS was added and sections kept in a moist chamber for 30 min. They were then rinsed with PBS and thoroughly washed with two changes of PBS of one hour each. The sections were mounted in a $10 \%$ solution of glycerol in PBS. The slides were examined with a Leitz Dialux microscope using transmitted ultraviolet light, dark ground condenser, exciter filters BG38 and KP490 and barrier filter interference green S525. The reaction sites showed bright green fluorescence. The controls were similar to those used for the immunoperoxidase technique.

All the sera used were obtained from Hoechst UK Limited.

\section{Results}

The summary of the findings are given in the Table. 
With the immunoperoxidase technique for immunoglobulins, complement, fibrinogen and albumin, brown deposits were found lining alveoli and within alveolar walls (Fig. 1), around intraalveolar macrophages (Fig. 2), within lumina of bronchi, bronchioli, and alveoli (Fig. 3), and within blood vessels (Fig. 4). Brown deposits were only found in plasma cells with the antisera of immunoglobulins (Fig. 5).
Sections of tonsillar tissue used as positive controls with immunoperoxidase always contained cells positive for the three classes of immunoglobulin but not for complement or fibrinogen. Lung sections in which the specific antisera were omitted did not stain and brown deposits in plasma cells present in most lung sections examined were only found with the antisera of immunoglobulins.
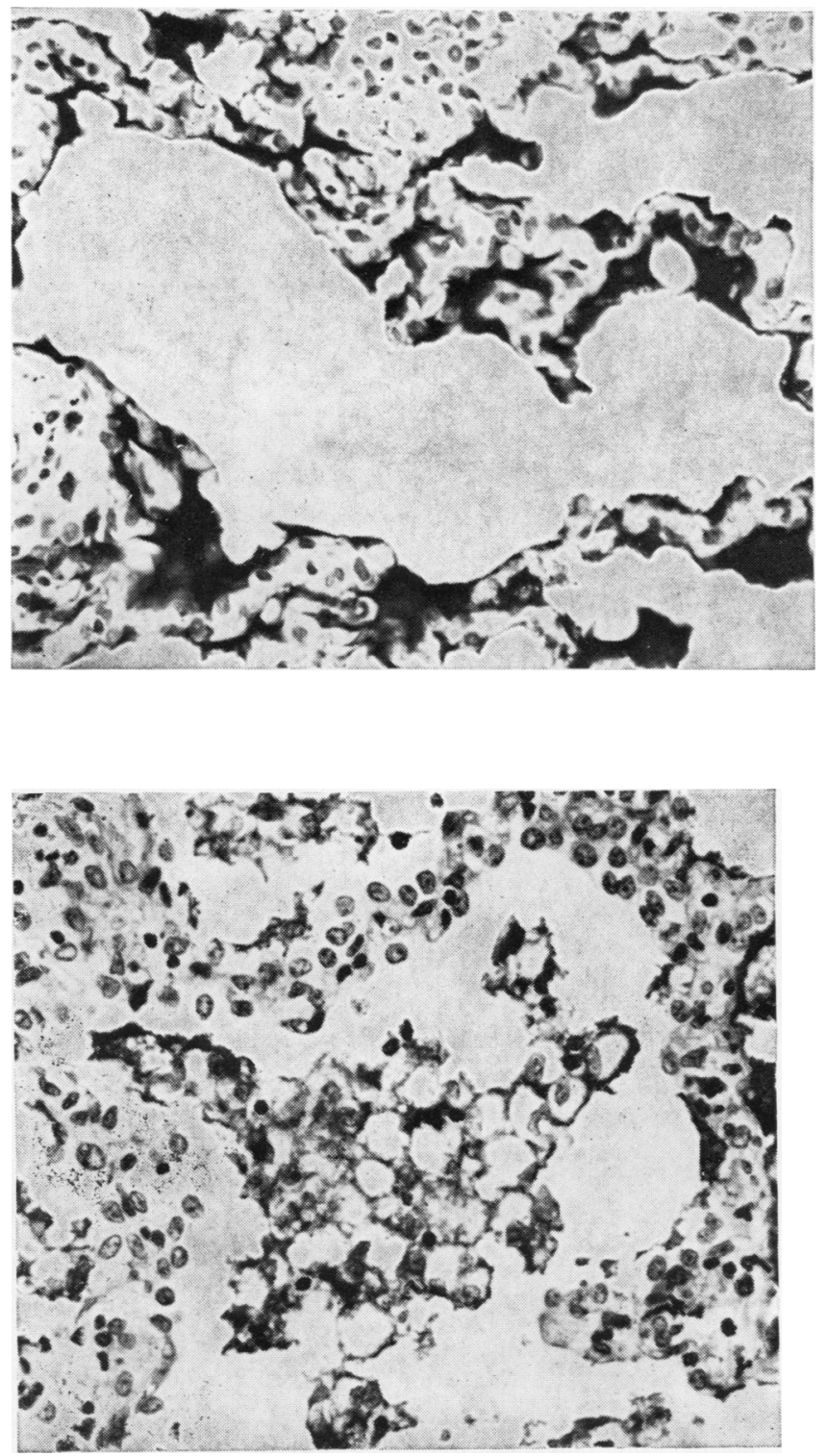

Fig. 1 Case 1. Linear deposits of IgG lining and within alveolar walls. Immunoperoxidase $\times 300$
Fig. 2 Case 4. Deposits of IgA around intra-alveolar macrophages. Immunoperoxidase $\times 300$. 


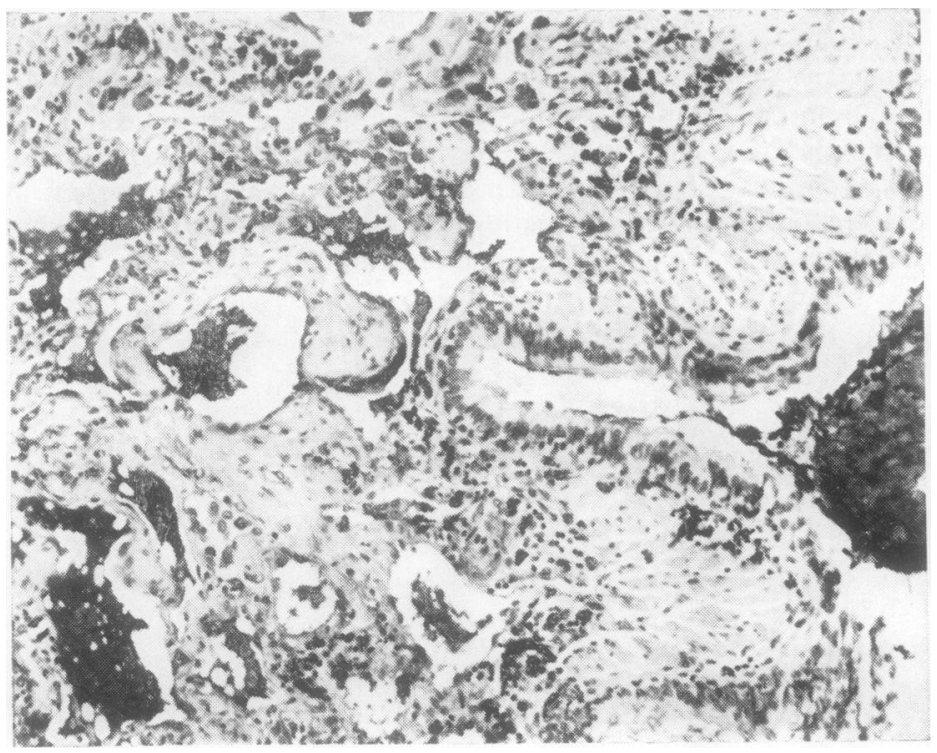

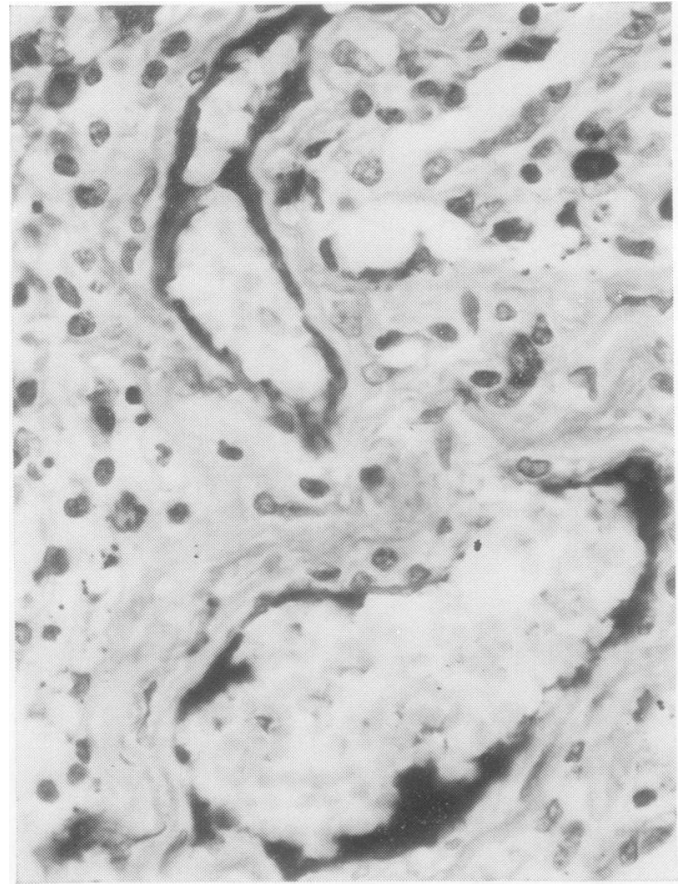

Fig. 4 Case 9. Intravascular deposit of IgG. Immunoperoxidase $\times 500$.

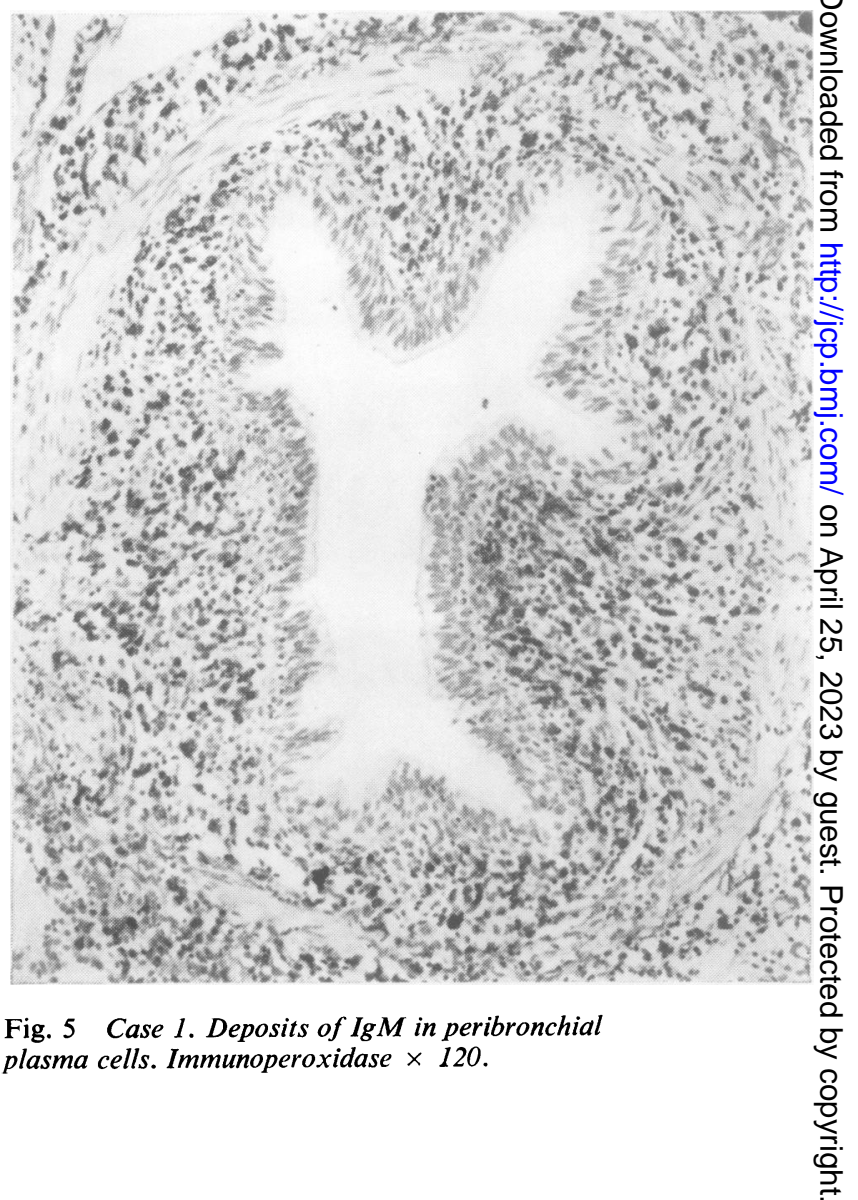

Fig. 3 Case 9. Intra-alveolar and intrabronchial deposits of $\mathrm{IgG}$. Immunoperoxidase $\times 120$. 


\section{Discussion}

Although the contrast between specific staining and background was sharper with IF the exact site of the deposits was more accurately identified with IP because the deposits were seen against a clearly identifiable background of tissues and cells. This is an important point in a tissue such as the lung which has a complex histological structure and thus many sites at which immune deposits may occur. Until now the significance of immune deposits, as demonstrated by IF, has been marred by the difficulty of their interpretation and exact localisation ${ }^{8}$ as well as by the necessity of using frozen sections of freshly removed tissue which limits the number of cases that can be examined. IP provides a method for the detailed study of a large number of cases, both retrospectively and prospectively.

The specificity of IP was confirmed by the controls used and by comparing the results obtained in 11 cases by this method with those obtained by IF (Table). All immune deposits seen with IF were positively stained by IP, but occasionally immune deposits, complement, and fibrinogen were found with IP and not by IF. These deposits seen by IP are unlikely to be the result of a non-specific or cross reaction because of the controls used and because of the complete absence of background staining.

Our results clearly show that in normal lung tissue (cases 21-27) immunoglobulins, complement, fibrinogen and albumin may sometimes be seen within blood vessels. The presence of immune deposits in other sites within the lung is always associated with disease. There are two possible mechanisms to account for extravascular immunoglobulins in diseased lung tissue. The first is non-specific and is due to exudation of serum proteins from blood vessels in inflamed tissues. The presence of albumin, a protein not involved in any immunological reaction, at the same sites as the immunoglobulins is evidence that this is the explanation in many of our cases (Table). The other mechanism is that an immunological reaction has occurred which is suggested by the presence of complement. However in cases in which $\mathrm{C} 3$ is present without $\mathrm{Clq}$ it is possible that complement could have been activated via the alternate pathway by aggregated $\operatorname{IgA}$ which may be present in the lung. Only in those cases in which C1q is present, usually with $\mathrm{C} 3$, can we suggest that an immunological mechanism may have occurred as C1q can only be formed by the activation of complement by immune complexes via the classic pathway. There were only three cases of UIP (cases $1,6,9)$ and two of sarcoidosis (cases 14, 15) in which C1q, C3, and IgG or IgM were apparently present at the same sites. Thus these are the only cases in which we think immune complexes may have been present. This is in agreement with other authors who have suggested that UIP may be an immune complex disease. ${ }^{115} 19$

Although we have only examined two cases of sarcoidosis our findings of deposits of possible immune complexes in these cases are intriguing. Immune complexes have been found in the circulation in patients with active sarcoidosis ${ }^{34-36}$ and in one case of sarcoidosis by IF within and around granulomata in the lung. ${ }^{37}$ In our cases using IP the deposits were confined to the lung parenchyma in areas of interstitial pneumonia and were not within the granulomata. Thus it is possible that the interstitial pneumonia often seen in sarcoidosis may also be an immune complex-mediated process.

Our studies have shown that IP is a reliable method for the identification of immunoglobulins, complement and fibrinogen in the lung. This technique should make it easier to clarify the diagnostic and possible pathogenic significance of immune deposits in lung disease.

We are grateful to Dr RA Maini for helpful discussion during the writing of this paper, and to Mr RS Barnett for the photomicrographs.

\section{References}

${ }^{1}$ Schatz M, Patterson R, Fink J. Immunologic lung disease. $N$ Engl J Med 1979;300:1310-20.

2 Sturgill BC, Westervelt FB. Immunofluorescence studies in a case of Goodpasture's sydrome. JAMA 1965;194:172-4.

${ }^{3}$ Beirne GJ, Octaviano GN, Kopp WL, Burns RO. Immunohistology of the lung in Goodpasture's syndrome. Ann Intern Med 1968;69:1207-12.

4 Markowitz AS, Battifora HA, Schwartz F, Aseron C. Immunological aspects of Goodpasture's syndrome. Clin Exp Immunol 1968;3:585-91.

${ }^{5}$ Koffler D, Sandson J, Carr R, Kunkel HG. Immunologic studies concerning the pulmonary lesions in Goodpasture's syndrome. Am J Pathol 1969;54:293-305.

6 Martinez JS, Kohler PF. Variant "Goodpasture's syndrome"?. The need for immunologic criteria in rapidly progressive glomerulonephritis and hemorrhagic pneumonitis. Ann Intern Med 1971;75:67-76.

${ }^{7}$ Teishman S, Briggs WA, Knieser MR, Enquist RW. Goodpasture's syndrome: two cases with contrasting early course and management. Am Rev Respir Dis 1976; 113:223-32.

${ }^{8}$ Hogan PG, Donato KJ, McEvoy JDS. Immunofluorescence studies of lung biopsy tissue. Am Rev Respir Dis 1978;118:537-45.

9 Johnson JP, Whitman W, Briggs WA, Wilson CB. Plasmapheresis and immunosuppressive agents in antibasement membrane antibody-induced Goodpasture's syndrome. Am J Med 1978;64:354-9.

${ }^{10}$ Border WA, Baehler RW, Bhathena D, Glassock RJ. IgA antibasement membrane nephritis with pulmonary hemorrhage. Ann Intern Med 1979;91:21-5.

11 Van Toorn DW. Coffee worker's lung. A new example of extrinsic allergic alveolitis. Thorax 1970;25:399-405.

12 Katz RM, Kniker WT. Infantile hypersensitivity pneu- 
monitis as a reaction to organic antigens. $N$ Engl $J$ Med $1973 ; 288: 233-7$.

1: Ghose T, Landrigan P, Killeen R, Dill J. Immunopathological studies in patients with farmer's lung. Clin Allergy 1974;4:119-29.

"Nagaya H, Elmore M, Ford CD. Idiopathic interstitial pulmonary fibrosis. An immune complex disease? $\mathrm{Am}$ Rev Respir Dis 1973;107:926-30.

${ }^{15}$ Dreisin RB, Schwarz MI, Theofilopoulos AN, Stanford RE. Circulating immune complexes in the idiopathic interstitial pneumonias. $N$ Engl J Med 1978;298:353-7.

${ }^{16}$ Schwarz MI, Dreisin RB, Pratt DS, Stanford RE. Immunofluorescent patterns in the idiopathic interstitial pneumonias. J Lab Clin Med 1978;91:929-38.

17 Pratt DS, Schwartz MI, May JJ, Dreisin RB. Rapidly fatal pulmonary fibrosis: the accelerated variant of interstitial pneumonitis. Thorax 1979;34:587-93.

${ }^{8}$ De Horatius RJ, Abruzzo JL, Williams RC. Immunofluorescent and immunologic studies of rheumatoid lung. Arch Intern Med 1972;129:441-6.

${ }^{19}$ Turner-Warwick M. Immunological aspects of systemic diseases of the lungs. Proc Roy Soc Med 1974;67:541-74.

20 Yeo PPB, Sinniah R. Lupus cor pulmonale with electron microscope and immunofluorescent antibody studies. Ann Rheum Dis 1975;34:457-60.

${ }^{21}$ Brentjens J, Ossi E, Albini B, et al. Disseminated immune deposits in lupus erythematosus. Arth Rheumatism 1977; 20:962-8.

${ }^{22}$ Pertschuk LP, Moccia LF, Rosen Y, et al. Acute pulmonary complications in systemic lupus erythematosus. Immunofluorescence and Light microscopic study. $\mathrm{Am} \mathrm{J} \mathrm{Clin}$ Pathol 1977;68:553-7.

2:3 Rodriguez-Iturbe B, Garcia R, Rubio L, Serrano H. Immunohistologic findings in the lung in systemic lupus erythematosus. Arch Pathol Lab Med 1977;101:342-4.

2 Eagen JW, Memoli VA, Roberts JL, Matthew GR, Schwartz MM, Lewis EJ. Pulmonary hemorrhage in systemic lupus erythematosus. Medicine 1978;57:545-60.

${ }^{25}$ Ainslie WH, Britt K, Moshipur JA. Maternal death due to lupus pneumonitis in pregnancy. Mt Sinai $J \operatorname{Med}(N Y)$ $1979 ; 46: 494-9$.

${ }^{26}$ Inoue T, Kanayama T. Ohe A. et al. Immunopathologic studies of pneumonitis in systemic lupus erythematosus. Ann Intern Med 1979;91:30-4.
${ }^{27}$ Iseman MD, Schwarz MI, Stanford RE. Interstitial pneumonia in angioimmunoblastic lymphadenopathy with dysproteinemia. A case report with special histopathologic studies. Ann Intern Med 1976;85:752-5.

${ }^{2 *}$ Capron JP, Marti R, Rey JL, et al. Fibrosing alveolitis and hepatitis $B$ surface antigen-associated chronic active hepatitis in a patient with immunoglobulin A deficiency. Am J Med 1979;66:874-8.

${ }^{29}$ May JJ, Schwarz MI, Dreisin RB. Idiopathic thrombocytopenic purpura occurring with interstitial pneumonitis. Ann Intern Med 1979;90:199-200.

${ }^{30}$ De Lellis RA, Sternberger LA, Mann RB, Banks PM. Nakane PK. Immunoperoxidase technics in diagnostic pathology. Report of a workshop sponsored by the National Cancer Institute. Am J Clin Pathol 1979;71: 483-8.

${ }^{31}$ Heyderman E. Immunoperoxidase technique in histopathology: application, methods, and controls. J Clin Pathol 1979;32:971-8.

${ }^{32}$ Liebow AA, Carrington CB. The interstitial pneumonias. In: Simon K, Potchen EJ, Le May M, eds. Frontiers of pulmonary radiology. New York: Grune and Stratton, 1968:102-41.

${ }^{33}$ Scadding JG, Hinson KEW. Diffuse fibrosing alveolitis (diffuse interstitial fibrosis of the lungs). Thorax 1967;22: 291-304.

${ }^{34}$ Hedfors E, Norberg R. Evidence for circulating immune complexes in sarcoidosis. Clin Exp Immunol 1974;16: 493-6.

${ }^{35}$ Gupta RC, Kuppers F, DeRemec RA, Huston KA, McDuffie FC. Pulmonary and extrapulmonary sarcoidosis in relation to circulating immune complexes. Am Rev Respir Dis 1977;116:261-6.

${ }^{36}$ Daniele RP, McMillan LJ, Dauber JH, Rossman MD. Immune complexes in sarcoidosis: a correlation with activity and duration of disease. Chest 1978;74:261-4.

${ }^{37}$ Ghose T, Landrigan P. Asif A. Localisation of immunoglobulin and complement in pulmonary sarcoid granulomas. Chest 1974;66:264-8.

Requests for reprints to: Dr B Fox, Department of Histopathology, Charing Cross Hospital Medical School, Fulham Palace Road, London W6 8RF, England. 